\title{
ADIPOQ single nucleotide polymorphisms and breast cancer in northeastern Mexican women
}

\author{
Ricardo M. Cerda-Flores ${ }^{1}$, Karen Paola Camarillo-Cárdenas², Gabriela Gutiérrez-Orozco ${ }^{3}$, \\ Mónica Patricia Villarreal-Vela ${ }^{2}$, Raquel Garza-Guajardo ${ }^{4}$, Marco Antonio Ponce-Camacho ${ }^{4}$, Ana Lilia Castruita-Ávila ${ }^{5}$, \\ Juan Francisco González-Guerrero ${ }^{6}$, Iram Pablo Rodríguez-Sánchez ${ }^{2}$, Ana Laura Calderón-Garcidueñas? \\ Hazyadee Frecia Rodríguez-Gutierrez ${ }^{6}$, Juan Carlos Arellano-Barrientos ${ }^{6}$, Oscar Vidal Gutierrez ${ }^{6}$, \\ Hugo Alberto Barrera Saldaña $a^{8,9,10}$ and María Lourdes Garza-Rodríguez ${ }^{6^{*}}$ (D)
}

\begin{abstract}
Background: Adiponectin gene (ADIPOQ) polymorphisms have been shown to affect adiponectin serum concentration and some have been associated with breast cancer (BC) risk. The aims of this study were to describe the frequency of single nucleotide polymorphisms (SNPS) of ADIPOQ in Mexican women with BC and to determine if they show an association with it.
\end{abstract}

Methods: DNA samples from 397 patients and 355 controls were tested for the ADIPOQ gene SNPs: rs2241766 (GT) and rs1501299 (GT) by TaqMan allelic discrimination assay. Hardy-Weinberg equilibrium (HWE) was tested. Multiple SNP inheritance models adjusted by age and body mass index (BMI) were examined for the SNP rs1501299.

Results: We found that in the frequency analysis of rs1501299 without adjusting the BMI and age, the genotype distribution had a statistically significant difference $(P=0.003)$. The T allele was associated with a $B C$ risk (OR, 1.99; 95\% Cl 1.13-3.51, Tा vs. GG; OR, 1.53; 95\% Cl 1.12-2.09, GT vs. GG). The SNP rs2241766 was in HW disequilibrium in controls. In conclusion, the rs1501299 polymorphism is associated with a BC risk.

Conclusions: Identification of the genotype of these polymorphisms in patients with BC can contribute to integrate the risk profile in both patients and their relatives as part of a comprehensive approach and increasingly more personalized medicine.

Keywords: Breast cancer, Single nucleotide polymorphisms, Adiponectin, ADIPOQ, Mexican women

\section{Background}

Breast cancer $(\mathrm{BC})$ is the most common cancer in adult women in the world [1]. Different risk factors have been implicated in $\mathrm{BC}$ initiation and progression such as overweight $(\mathrm{OW})$ and obesity $(\mathrm{OB})[2]$. OB is increasingly

\footnotetext{
* Correspondence: maria.garzarg@uanl.edu.mx

${ }^{6}$ Facultad de Medicina y Hospital Universitario "Dr. José Eleuterio González", Centro Universitario Contra el Cáncer (CUCC), Universidad Autonoma de Nuevo Leon, Monterrey, Nuevo León, Mexico

Full list of author information is available at the end of the article
}

recognized as an oncogenic factor and is associated with many metabolic disorders, such as type 2 diabetes mellitus, coronary heart disease, and hypertension, and with cancer in different tissues, such as colon, prostate, and breast [3-5]. Moreover, it has been shown that excess adipose tissue promotes metastasis and recurrence of BC and is associated with increased mortality.

Adipocytes produce adiponectin and leptin, two highly expressed adipokines that have opposing effects on immune cell function [6]. Adiponectin is secreted

(c) The Author(s). 2020 Open Access This article is licensed under a Creative Commons Attribution 4.0 International License, which permits use, sharing, adaptation, distribution and reproduction in any medium or format, as long as you give appropriate credit to the original author(s) and the source, provide a link to the Creative Commons licence, and indicate if changes were made. The images or other third party material in this article are included in the article's Creative Commons licence, unless indicated otherwise in a credit line to the material. If material is not included in the article's Creative Commons licence and your intended use is not permitted by statutory regulation or exceeds the permitted use, you will need to obtain permission directly from the copyright holder. To view a copy of this licence, visit http://creativecommons.org/licenses/by/4.0/ The Creative Commons Public Domain Dedication waiver (http://creativecommons.org/publicdomain/zero/1.0/) applies to the data made available in this article, unless otherwise stated in a credit line to the data. 
exclusively by adipose tissue and has antineoplastic, antiinflammatory, anti-oxidant, and anti-apoptotic roles [7]. This hormone also regulates estrogen, tumor necrosis factor (TNF), and insulin growth factor (IGF) secretion [6, 8-10]. Adiponectin serum concentrations are decreased in obese and diabetic subjects [10]. Studies support evidence that decreased adiponectin serum concentration may explain the increased risk of $\mathrm{BC}$ in $\mathrm{OB}^{9}$ and that this hormone is a potential diagnostic and prognostic BC biomarker [9].

$A D I P O Q$ polymorphisms have been shown to affect adiponectin serum concentrations, and some have been associated with $\mathrm{BC}$ risk [10-12]. Adipokines are associated with several types of obesity-related cancers [1317]. Previous studies found that homozygous carriers of the T allele of SNP rs1501299 had the highest concentration of adiponectin compared to the GG or TG genotypes [10, 18]. Also, an association of the rs2241766 TG and GG genotypes with increased adiponectin serum concentration and with a decreased risk for breast cancer was reported [10]. SNPs that cause lower adiponectin serum concentrations are associated with increased cancer risk; also, adiponectin levels are inversely correlated with adiposity. Decreased adiponectin serum concentrations may explain the increased risk of breast cancer in obesity $[10,18,19]$.

The objectives of this hospital case-control study were: 1. To describe the frequency of two SNPs, rs2241766 (+ $45 \mathrm{~T}>\mathrm{G})$ and rs1501299 (+276G > T) of ADIPOQ in a sample of Mexican women from northeastern Mexico with and without $\mathrm{BC}$, and 2 . To determine any association between these polymorphisms and $\mathrm{BC}$ risk.

\section{Methods}

\section{Approval from the scientific and ethics committees}

The study was conducted in accordance with the Declaration of Helsinki, and the protocol was approved by the Institutional Ethics Committee of the University Hospital (registration no. BI10-002). All patients were invited to participate in the research project, an interview was performed and once the patients agreed to participate, they signed an informed consent. Afterwards, clinical and epidemiological information was collected, and blood samples were taken.

\section{Study design and population}

A hospital case-control study was carried out. Patients were selected among women receiving chemotherapy at two institutions located in Monterrey City, Mexico: the Centro Universitario Contra el Cáncer (Hospital Universitario "Dr. José E. González" (HU), of the Universidad Autónoma de Nuevo León) and the Hospital de Especialidades \#25 (Instituto Mexicano del Seguro Social (IMSS)). Both are referral centers for patients affected by this neoplasm who come from five states located in Northeast Mexico (Nuevo León, San Luis Potosi, Zacatecas, Coahuila, and Tamaulipas).

\section{Patient group}

All BC patients were older than 18 years, had a confirmatory biopsy, and accepted to participate in the study and signed an informed consent. Because we are studying a low-penetrance gene $(A D I P O Q)$, the study included only patients with sporadic breast cancer, thus, patients with a family history of $\mathrm{BC}$ were excluded. Pregnant women were also excluded.

Female BC patients attending the oncology clinics of the two participating hospitals who fulfilled inclusion criteria were invited by the oncologist to participate in the project. An interview was conducted to explain the protocol to the patients and subsequently, women who accepted to participate signed the consent letter. Blood samples were collected in the areas of chemotherapy and consultation. Epidemiological and clinical information was also collected. Only three patients refused to participate in the study. Most of the patients of the case group 288 (72.5\%) and all the controls 355 (100\%) came from the IMSS, the rest of the cases came from the HU (109/27.5\%).

\section{Control group}

Controls were women older than 18 years of age, without a history of cancer and a BI-RADS 1-2 mammogram who signed an informed consent. Individuals with a family history of $\mathrm{BC}$ and pregnant women were excluded.

All control group women were recruited in the radiology areas. They attended a follow-up mammography or were referred for timely detection of cancer by mammography. If the women fulfilled the inclusion criteria, they were invited to participate by interview and after signing the informed consent, a blood sample was taken in the radiology area and epidemiological and clinical information was collected. All 397 patients and 355 controls were Mexican women whose four grandparents were born in Northeast Mexico (Nuevo León, San Luis Potosi, Zacatecas, Coahuila, and Tamaulipas).

\section{DNA preparation}

Genomic DNA was extracted from whole peripheral blood either with the QIAmp DNA Blood Kit (Cat No. 51104 Qiagen Inc., CA, USA) according to the manufacturer's instructions, or using the TSNT method followed by phenol-chloroform extraction and ethanol precipitation [20]. DNA concentrations was measured by NanoDrop 8000 Spectrophotometer (Thermo Scientific, USA). Concentrations was adjusted to $50 \mathrm{ng} / \mu \mathrm{l}$ in purified nuclease-free water. 


\section{Analysis of DNA polymorphisms}

Samples from patients $(n=397)$ and controls $(n=355)$ were tested for the ADIPOQ gene SNPs: rs2241766 (GT) and rs1501299 (GT). All assayed polymorphic sites were genotyped using the TaqMan allelic discrimination assay (Assay ID: C_26426077_10 for rs2241766 and C 7497299_10 for rs1501299, Applied Biosystems, USA). All polymerase chain reactions (PCRs) were done in a volume of $10 \mu \mathrm{l}$ containing: $5 \mu \mathrm{l}$ of TaqMan universal PCR Master Mix 2X, $2 \mu \mathrm{l}$ of DNA (100 ng), $0.2 \mu \mathrm{l}$ of TaqMan SNP Genotyping Assays 20X, and $2.8 \mu \mathrm{l}$ of nuclease free water. Thermal cycling conditions were 10 min at $95^{\circ} \mathrm{C}$, and 42 cycles each of $95^{\circ} \mathrm{C}$ for $15 \mathrm{~s}$, and $60^{\circ} \mathrm{C}$ for $1 \mathrm{~min}$. The Step One Real Time System (Applied Biosystems, USA) was used for genotyping.

\section{Statistical analysis}

IBM SPSS version 24.0 was used for descriptive statistical analysis. First, participant characteristics were summarized as arithmetic means with standard deviation (SD) for continuous variables and counts and percentages for categorical variables. Second, the $p$-values of continuous variables were determined by unpaired $t$-test, for categorical variables, a chi- square test was used. Third, Hardy-Weinberg equilibrium (HWE) was tested with the public software developed by Tim M Strom and Thomas F. Wienker (http://ihg.gsf.de/cgi-bin/hw/hwa1. $\mathrm{pl}$ ) without adjustment by age and BMI. Fourth, Multiple SNP inheritance models (codominant, dominant, recessive, overdominant and Log-additive) adjusted by age and BMI were examined to determine odds ratio (OR) and 95\% confidence intervals (CI) (http://bioinfo.iconcologia.net/snpstats/start.htm). Given that this software has a limited sample size to run, a random woman was selected in cases ( $n=258$ of 397) and control $(n=258$ of 355) groups; in order to randomly select, the EPIDAT package V4.1 was used. A p-value less than 0.05 was considered significant.

\section{Results}

\section{Clinical and pathological characteristics}

Demographic and clinical characteristics of the study population are shown in Table 1 . The mean ages $( \pm \mathrm{SD})$ were $52.4( \pm 12.0)$ and $49.5( \pm 10.9)$ for cases $(n=397)$ and controls $(n=355)$, respectively. Of the 12 characteristics analyzed, age at baseline interview, BMI, breastfeeding duration, menopausal status, and use of oral contraceptives showed statistical differences. Pathological characteristics are shown in the supplementary material.

Invasive ductal carcinoma (IDC) was the most frequent cancer type (71.8\%). The most frequent clinical stage was IIIB with $17.1 \%$. The most common site of metastasis was bone. The majority of cases had modified radical mastectomy (MRM) surgery (65.8\%) and 2.5\% of women had bilateral cancer at diagnosis. Supplementary Table 1.

For biopsies with available immunohistochemistry $(n=274)$ for estrogen and progesterone receptors and HER2-neu, the information is shown in Table 2. In 82 cases $(30 \%)$, a triple negative profile was observed.

\section{The allele and genotype frequencies of ADIPOQ polymorphisms}

The allele and genotype frequencies for the rs1501299 and rs2241766 polymorphisms are summarized in Table 3. To carry out this analysis, 258 cases and 258 controls were randomly select, without adjusted by age and BMI. No significant deviations from HWE were found for the SNP rs1501299. The SNP rs2241766 was in HW disequilibrium in control women $(p=0.005)$. When we performed the frequency analysis without adjusting the BMI and age, the genotype distribution exhibited a statistically significant difference between cases and controls $(P=0.003$ and $P=$ 0.0003 for rs1501299 and rs2241766, respectively) and the $\mathrm{T}$ allele of rs1501299 was associated with $\mathrm{BC}$ risk (OR 1.99; 95\% CI 1.13-3.51, TT vs GG; OR 1.53; 95\% CI 1.122.09, GT vs GG).

Subsequently, we performed the multiple SNP inheritance models of rs1501299 adjusted by age and BMI. With the codominant model, the genotype distribution exhibited a statistically significant difference between cases and controls $(p=8 \mathrm{e}-04)$ and the T allele of rs1501299 was associated with BC protection (OR 0.55; 95\% CI 0.34-0.80 GT and OR 0.39; 95\% CI 0.20-0.76 TT) (Table 4).

The rs2241766 G allele (GT and GG genotypes) was associated with a decreased risk for BC (OR 0.20; 95\% CI $0.07-0.51$, GG vs TT; add the OR and 95\% CI for TG). However, because rs2241766 was out of HWE, these results should be considered with caution. Because this polymorphism is not in HW equilibrium, no multiple SNP inheritance models analysis was made.

We compared our genotypic frequencies with the frequencies reported for a population of 46 Mexican individuals from the National Center for Biotechnology Information (NCBI) web page [21]. The SNP rs2241766 frequencies in the controls $(0.22 \mathrm{G}$ allele and $0.78 \mathrm{~T}$ allele) were compared with the reported frequencies for the NCBI Hispanic population $(0.28$ for allele $\mathrm{G}$ and 0.71 for allele $\mathrm{T}$ ). A chi-square test was applied and a significant difference between both populations was found for $\operatorname{rs} 2241766\left(X^{2}=10.70, p=0.005\right.$ when comparing the cases and $X^{2}=106.28, p=1 \times 10-7$ when comparing the controls). Also, rs1501299 frequencies in the controls $(0.76 \mathrm{G}$ allele and $0.24 \mathrm{~T}$ allele) were compared with the reported frequencies for the NCBI Hispanic population ( 0.76 for allele $\mathrm{G}$ and 0.24 for allele $\mathrm{T}$ ). A chi-square test was applied, and we did not find a 
Table 1 Comparison of 12 characteristics in case and control groups

\begin{tabular}{|c|c|c|c|}
\hline \multirow[t]{3}{*}{ Characteristics } & \multicolumn{2}{|l|}{$(n=752)$} & \multirow{3}{*}{$\begin{array}{l}p- \\
\text { value }\end{array}$} \\
\hline & Case $(n=397)$ & Control $(n=355)$ & \\
\hline & Mean \pm SD or $\%$ & Mean \pm SD or $\%$ & \\
\hline \multicolumn{4}{|l|}{ Demographic factors } \\
\hline Age at baseline interview (years) & $52.5 \pm 12$ & $49.5 \pm 10.9$ & $0.009^{\mathrm{a}}$ \\
\hline Height (m) & $1.56 \pm 0.07$ & $1.60 \pm 0.07$ & $0.871^{\mathrm{a}}$ \\
\hline $\mathrm{BMI}>30\left(\mathrm{~kg} / \mathrm{m}^{2}\right)$ & & & $0.001^{b}$ \\
\hline Yes & 43.1 & 29.9 & \\
\hline No & 50.1 & 68.7 & \\
\hline$n / a$ & 6.8 & 1.4 & \\
\hline \multicolumn{4}{|l|}{ Reproductive factors } \\
\hline Age at menarche (years) & $12.8 \pm 1.6$ & $12.7 \pm 1.5$ & $0.379^{\mathrm{a}}$ \\
\hline Age at first childbirth (years) & $23.1 \pm 5.6$ & $23.4 \pm 5.3$ & $0.398^{\mathrm{a}}$ \\
\hline Number of children born alive & $3.3 \pm 2$ & $3.2 \pm 2.2$ & $0.115^{\mathrm{a}}$ \\
\hline \multicolumn{4}{|l|}{ Children } \\
\hline Yes & 85.4 & 88.7 & $0.509^{b}$ \\
\hline No & 14.6 & 11.3 & \\
\hline Breast-feeding & & & $0.052^{\mathrm{b}}$ \\
\hline$\leq 30$ years old & 56.4 & 47.0 & \\
\hline$\geq 30$ years old & 7.8 & 4.8 & \\
\hline $\mathrm{n} / \mathrm{a}$ & 35.8 & 48.2 & \\
\hline Breast-feeding duration (months) & $12.2 \pm 13.0$ & $14.2 \pm 22.2$ & $0.002^{\mathrm{a}}$ \\
\hline Menopausal status & & & $0.001^{b}$ \\
\hline Yes & 63.2 & 44.2 & \\
\hline No & 33.0 & 55.5 & \\
\hline$n / a$ & 3.8 & 0.3 & \\
\hline Age at menopause & $44.9 \pm 5.7$ & $45.9 \pm 6.3$ & $0.797^{\mathrm{a}}$ \\
\hline \multicolumn{4}{|l|}{ Hormonal factors } \\
\hline Use of oral contraceptive & & & $0.001^{b}$ \\
\hline Yes & 30.2 & 21.4 & \\
\hline No & 66.0 & 78.6 & \\
\hline$n / a$ & 3.8 & 0.0 & \\
\hline
\end{tabular}

$S D$ standard deviation; $B M I$ Body mass index; $n / a$ not available; $t$-test ${ }^{\mathrm{a}}$, chi-square test ${ }^{\mathrm{b}}$

significant difference between both populations $\left(X^{2}=\right.$ $\left.0.006, p=0.997, X^{2}=3.16, p=0.206\right)$ respectively.

\section{Association of BMI with ADIPOQ genotypes}

We found a statistically significant BMI difference between women with breast cancer and the control group (Table 1). In order to identify if the BMI was associated with the rs1501299 and rs2241766 genotypes, we performed a univariate general lineal model. The result between cases and controls was a F vale of $6.29(p=0.012)$, for the $\operatorname{rs} 2241766(\mathrm{~F}=1.473, p=0.338)$ and the s1501299 ( $\mathrm{F}=2.417, p=0.131)$. When we realized the interactions between BMI and $\mathrm{rs} 1501299$ ( $\mathrm{f}=0.30, p=$ $0.77)$ and $\operatorname{rs} 2241766(\mathrm{f}=0.18, p=0.84)$, no significance association was found.

\section{Discussion}

In this study, we found an association between rs1501299 in ADIPOQ and BC risk in Mexican women with an OR of 1.53 (95\% CI, 1.12-2.09) for the GT

Table 2 Breast cancer tumor immunohistochemistry $(n=274)$

\begin{tabular}{lllll}
\hline Immunohistochemistry & ER status $\mathbf{n}(\%)$ & PR status $\mathbf{n}(\%)$ & Her-2 status $\mathbf{n}$ (\%) & TNBC status $\mathbf{n}(\%)$ \\
\hline Positive & $149(54.4)$ & $127(46.4)$ & $114(41.6)$ & $82(29.9)$ \\
Negative & $125(45.6)$ & $147(53.6)$ & $165(57.0)$ & $192(70.1)$ \\
\hline
\end{tabular}

ER Estrogen receptor; PR Progesterone receptor, TNBC Triple Negative Breast Cancer 
Table 3 Frequencies of adiponectin polymorphism in Mexican Women wihout adjusted by age and BMI

\begin{tabular}{|c|c|c|c|c|c|c|}
\hline Polymorphism & Frequencies & Cases \% & Controls \% & $p$-value (cases vs control) & OR & $95 \%$ IC \\
\hline \multirow{9}{*}{$\begin{array}{l}\text { rs1501299 } \\
(+276 G>T)\end{array}$} & Genotype & $n=397$ & $n=355$ & & & \\
\hline & $\mathrm{GG}^{\mathrm{S}}$ & 44.4 & 58.3 & 0.003 & Reference & \\
\hline & GT & 45.6 & 35.5 & & 1.53 & $1.12-2.09$ \\
\hline & $\pi$ & 10.0 & 6.2 & & 1.99 & $1.12-3.51$ \\
\hline & $x^{2}$ & 0.434 & 0.231 & & & \\
\hline & $p$-value HWE & 0.51 & 0.63 & & & \\
\hline & Allele & & & & & \\
\hline & G & 0.671 & 0.761 & & & \\
\hline & T & 0.329 & 0.239 & & & \\
\hline \multirow{9}{*}{$\begin{array}{l}\text { rs2241766 } \\
(\text { Gly15Gly, + 45 T > G) }\end{array}$} & Genotype & $n=397$ & $n=355$ & & & \\
\hline & $\pi^{S}$ & 71.0 & 62.8 & 0.0003 & Reference & \\
\hline & TG & 27.2 & 29.6 & & 0.81 & $0.51-1.12$ \\
\hline & GG & 1.8 & 7.6 & & 0.20 & $0.07-0.51$ \\
\hline & $x^{2}$ & 0.8386 & 7.887 & & & \\
\hline & p-value HWE & 0.360 & 0.005 & & & \\
\hline & Allele & & & & & \\
\hline & T & 0.847 & 0.776 & & & \\
\hline & G & 0.153 & 0.224 & & & \\
\hline
\end{tabular}

HWE Hardy-Weinberg Equilibrium

genotype and 1.99 (95\% CI, 1.13-3.51) for TT vs. GG. On the other hand, when information was analyzed adjusted by BMI and age using the five models, all of them showed an OR lower than one, considering a protective association. Besides the codominant model showed the lowest significant $p$-value (8e-04) and an AIC value of 684.27 with an OR of 0.55 (95\% CI $0.34-0.80$ ) for GT genotype, and an OR of 0.39 (95\% CI 0.20-0.76) for TT vs GG.

In 2013, Kaklamani et al. found that rs1501299 was associated with $\mathrm{BC}$ risk not only in Caucasian population, but also in African American women [11]. Kaklamani associated the genotypes GG and TG with risk of breast cancer and reported that the TT genotype increases circulating adiponectin serum concentrations; this could explain the protective effect of genotype $\mathrm{TT}$ observed in our study [11]. Another study reported that variation in the ADIPOQ gene has effects on other types of cancer. They found that the $\mathrm{T}$ variation may have a protective effect in the development of endometrial cancer [22]. There is another study with opposite results that report that the GG genotype was associated with a higher adiponectin serum concentration in Kuwait [18]. Gui et al. found no association between genotypes of rs1501299 and adiponectin [23]. Also, there are reports that show an inverse association between adiponectin

Table 4 ADIPOQ rs1501299 polymorphism using the multiple SNP inheritance models adjusted by age and BMI

\begin{tabular}{|c|c|c|c|c|c|c|}
\hline Model & Genotype & $\begin{array}{l}\text { Cases \% } \\
n=258\end{array}$ & $\begin{array}{l}\text { Controls } \\
n=258\end{array}$ & $\begin{array}{l}\text { OR } \\
(95 \% \mathrm{Cl})\end{array}$ & $p$-value & AIC \\
\hline \multirow[t]{3}{*}{ Codominant } & GG & 41.1 & 58.1 & 1.00 & $8 e-04$ & 684 \\
\hline & GT & 47.3 & 35.7 & $0.55(0.34-0.80)$ & & \\
\hline & $\pi$ & 11.6 & 6.2 & $0.39(0.20-0.76)$ & & \\
\hline \multirow[t]{2}{*}{ Dominant } & GG & 41.1 & 58.1 & 1.00 & $3 e-04$ & 683.1 \\
\hline & GT - TT & 58.9 & 41.9 & $0.52(0.36-0.74)$ & & \\
\hline \multirow[t]{2}{*}{ Reccesive } & $\mathrm{GG}-\mathrm{GT}$ & 88.4 & 93.8 & 1.00 & 0.04 & 692.1 \\
\hline & $\pi$ & 11.6 & 6.2 & $0.51(0.27-0.98)$ & & \\
\hline \multirow[t]{2}{*}{ Overdominant } & $G G-\Pi$ & 52.7 & 64.3 & 1.00 & 0.012 & 690 \\
\hline & GT & 47.3 & 35.7 & $0.63(0.44-0.90)$ & & \\
\hline Log-additive & - & - & - & $0.59(0.45-0.78)$ & $2 e-04$ & 682.5 \\
\hline
\end{tabular}


concentrations within breast tumors and tumor stage [24]. To date, reports of the association of rs1501299 genotypes with serum adiponectin levels are contradictory. $\mathrm{Al}$ Khaldi et al. reported that the $\mathrm{T}$ allele and TT genotype of rs1501266 reduce adiponectin levels in serum [18].

Another study reports no association between $A D I$ $P O Q$ SNPs and BC in American white women [25]. Genotypes TG and GG of SNP rs2241766 have also been associated with a decreased risk for BC when compared to the TT genotype, the rs 2241766 variation with the $\mathrm{G}$ allele and the TG and TG + GG genotypes may have a protective effect in ductal infiltrating breast cancer in Mexican women [26].

In our study, the rs2241766 polymorphism was in HW disequilibrium in controls, so it is not possible to confidently associate it with breast cancer risk. The allelic discrimination plots obtained in the real time PCR were clean and we did not find differences between duplicates.

Some authors have also reported HW disequilibrium in different populations for the rs2241766 polymorphism [24]. The main causes of HW disequilibrium in controls were selection bias or a competing risk of death associated with the mutant gene [25].

We performed a general lineal model to identify if the BMI was associated with the polymorphism. We were able to identify that the polymorphism is associated with breast cancer risk, but not the BMI.

In our study, the controls did not come from the general population but from the radiology area, which may have contributed to selection bias and may partly explain the genotypic imbalance in the case of rs2241766. Another disadvantage of this study is that we were unable to analyze serum ADIPOQ levels due to variability in pre-analytical processes.

Further studies are needed to examine the association of adiponectin serum concentrations with the different gene polymorphisms [10, 19], particularly in Mexican populations.

We estimated associations between SNPs in ADIPOQ and $\mathrm{BC}$ risk in a hospital case-control study of Mexican women. To our knowledge, our study is the largest in Mexican population (397 cases and 355 controls) evaluating $A D I P O Q$ SNPs in $\mathrm{BC}$ risk.

The Mexican population is Mestizo, and it is important to characterize the distribution of $\mathrm{BC}$ risk polymorphisms. Detection of SNP rs1501299 in the Mexican population may play an important role as a $\mathrm{BC}$ risk biomarker. Other reports in Mexican women found a positive relation with SNP rs1501299, and the response to chemotherapeutic treatment in patients with BC [19].

Mexico is a developing country where the use of genetic tests is not routine and SNP detection will be useful to support potential benefits of personalized medicine for Mexican population.

\section{Conclusions}

In conclusion, we confirmed that rs1501299 polymorphism is associated with $\mathrm{BC}$ risk in a large series of Mexican women. The identification of the genotype of these polymorphisms in patients with breast cancer can contribute to integrate the risk profile in both patients and their relatives as part of a comprehensive approach and an increasingly more personalized medicine.

\section{Supplementary information}

Supplementary information accompanies this paper at https://doi.org/10. 1186/s12881-020-01125-8.

Additional file $\mathbf{1}$ Table S1. Clinical-pathological characteristics in the case group.

\section{Abbreviations}

ADIPOQ: Adiponectin gene; BC: Breast cancer; SNPs: Single nucleotide polymorphisms; HWE: Hardy-Weinberg equilibrium; BMI: Body mass index; OW: Overweight; OB: Obesity; TNF: Tumor necrosis factor; IGF: Insulin growth factor; IMSS: Instituto Mexicano del Seguro Social; SDs: Standard deviations; ORs: Odds ratios; Cl: Confidence intervals; IDC: Invasive ductal carcinoma; MRM: Modified radical mastectomy; NCBI: National Center of Biotechnology Information

\section{Acknowledgments}

We are grateful for the support provided by the Conacyt National Biobank Laboratory. The authors thank the patients for their valuable participation in this study. Special thanks to the authorities of the participating hospitals: The Hospital Universitario "Dr. José Eleuterio González" from The Universidad Autónoma de Nuevo León, and to the "Hospital de Especialidades No. 25" and "Hospital General de Zona No. 17" from the Instituto Mexicano del Seguro Social for their cooperation. The authors gratefully acknowledge the critical reading of the manuscript by Sergio Lozano-Rodríguez, MD.

We thank the University of Texas Rio Grande Valley (UTRGV) for accepting this work for its presentation at the Research Symposium 2019 of the School of Medicine. The abstract has been published in the symposium program on https://issuu.com/utrgv/docs/2019-symposium-program.

\section{Authors' contributions}

MLGR, JFGG, and OVG designed the study and obtained funding for this study. GGO, RGG, MAPC, ALCA, JFGG, OVG, and MLGR recruited patients for the study. KPCC, MPW, JCAB, RGG, MAPC, and HFRG carried out the DNA extractions and sample storage in the biobank. HFRG, RMCF, and MLGR designed the sample database, and performed the statistical analysis. KPCC, GGO, IPRS, JCAB and MPW performed the q-PCR and PCR assays. MLGR, HFRG, OVG, JFGG, HABS, ALCA, and RMCF performed interpretation of data analysis. MLGR, RMCF, HABS, OVG, JFGG, and KPCC drafted the manuscript. All authors substantively read/revised/corrected, and approved the final manuscript.

\section{Funding}

The present work has been supported by grants from the Universidad Autonoma de Nuevo Leon, UANL (PAICYT-CS816-11 and PAICYT-SA814-19) awarded to MLGR.

\section{Availability of data and materials}

All data generated or analyzed during this study are included in this manuscript.

The sequences of the SNP were obtained from the NCBI GenBank database (https://www.ncbi.nlm.nih.gov/genbank). The reference genome was GRCh38.p12 and the accession numbers for SNP are: NG_021140.1:g.15430 T> G for rs2241766, and NG_021140.1:g.15661G > T for rs1501299. 


\section{Ethics approval and consent to participate}

All individual participants voluntarily joined this study and provided written informed consent. Ethical approval for this investigation was obtained from the Institutional Ethics Committee of the Hospital Universitario "Dr. José Eleuterio González" (registration number: Bl10-002).

\section{Consent for publication}

Not applicable.

\section{Competing interests}

The authors declare that they have no competing interests.

\section{Author details}

${ }^{1}$ Facultad de Enfermería, Universidad Autonoma de Nuevo Leon, Monterrey, Nuevo León, Mexico. ²Facultad de Ciencias Biológicas, Universidad Autonoma de Nuevo Leon, Monterrey, Nuevo León, Mexico. ${ }^{3}$ Facultad de Medicina y Hospital Universitario "Dr. José Eleuterio González", Departamento de Bioquímica Monterrey, Universidad Autonoma de Nuevo Leon, Monterrey, Nuevo León, Mexico. ${ }^{4}$ Facultad de Medicina y Hospital Universitario "Dr. José Eleuterio González", Servicio de Anatomía Patológica y Citopatología, Universidad Autonoma de Nuevo Leon, Monterrey, Nuevo León, Mexico. ${ }^{5}$ Mexican Institute of Social Security, Hospital de Especialidades No 25, Monterrey, Nuevo León, Mexico. ${ }^{6}$ Facultad de Medicina y Hospital Universitario "Dr. José Eleuterio González", Centro Universitario Contra el Cáncer (CUCC), Universidad Autonoma de Nuevo Leon, Monterrey, Nuevo León, Mexico. ${ }^{7}$ Facultad de Medicina, Universidad Veracruzana, Boca del Río, Veracruz, Mexico. ${ }^{8}$ Vitagénesis SA, Monterrey, Nuevo León, Mexico. ${ }^{9}$ LANSEIDI FarbBiotec at Innbiogem, Monterrey, Nuevo León, Mexico. ${ }^{10} \mathrm{Centro}$ de Biotecnología Genómica del Instituto Politécnico Nacional (IPN), Reynosa, Tamaulipas, Mexico.

Received: 27 February 2020 Accepted: 17 September 2020

Published online: 25 September 2020

\section{References}

1. GLOBOCAN. Estimated cancer incidence, mortality and prevalence worldwide in 2012. Globocan (2012). Available at: http://globocan.iarc.fr/ Pages/fact_sheets_population.aspx.

2. Nattenmüller CJ, et al. Obesity as risk factor for subtypes of breast cancer: results from a prospective cohort study. BMC Cancer. 2018;18:1-8.

3. Klein $\mathrm{S}$, Wadden T, Sugerman HJ. AGA technical review on obesity. Gastroenterology. 2002;123:882-932.

4. Sorisky A. Molecular links between obesity and cardiovascular disease. Am J Ther. 2002;9:516-21.

5. Wolk A, et al. A prospective study of obesity and cancer risk (Sweden) Cancer Causes Control. 2001;12:13-21.

6. Deng T, Lyon CJ, Bergin S, Caligiuri MA, Hsueh WA. Obesity, inflammation, and Cancer. Annual Rev Pathol. 2016;11.

7. Woodward L, Akoumianakis I, Antoniades C. Unravelling the adiponectin paradox: novel roles of adiponectin in the regulation of cardiovascular disease. Br J Pharmacol. 2017;174:4007-20.

8. Ouchi N, Kihara S, Arita Y, Maeda K, Kuriyama H, Okamoto Y, Hotta K, Nishida M, Takahashi M, Nakamura T, Yamashita S, Funahashi T, Matsuzawa Y. Novel modulatior for endothelial adhesion molecules: adipocyte-derived plasma protein adiponectin. Circulation. 1999;100:2473-6.

9. Dalamaga M. Obesity, insulin resistance, adipocytokines and breast cancer: new biomarkers and attractive therapeutic targets. World J Exp Med. 2013;3: 0 .

10. Kaklamani VG, et al. Variants of the adiponectin and adiponectin receptor 1 genes and breast cancer risk. Cancer Res. 2008;68:3178-84.

11. Kaklamani VG, et al. Adiponectin pathway polymorphisms and risk of breast cancer in Africa Americans and Hispanics in the Womens health initiative. Breast Cancer Res Treat. 2013;139:461-8.

12. Dalamaga M, Diakopoulos KN, Mantzoros CS. The role of adiponectin in cancer: a review of current evidence. Endocr Rev. 2012;33:547-94.

13. Dahran N, Szewczyk-Bieda M, Vinnicombe S, Fleming S, Nabi G. Periprostatic fat adipokine expression is correlated with prostate cancer aggressiveness in men undergoing radical prostatectomy for clinically localized disease. BJU Int. 2018;123:985-94.

14. Morris EV, Edwards CM. Adipokines, adiposity, and bone marrow adipocytes: dangerous accomplices in multiple myeloma. J Cell Physiol. 2018;233:9159-66.
15. Zhu H, et al. Circulating and adipose tissue mRNA levels of zinc-a2glycoprotein, leptin, high-molecular-weight adiponectin, and tumor necrosis factor-alpha in colorectal cancer patients with or without obesity. Front Endocrinol (Lausanne). 2018;9.

16. Lee $\mathrm{CH}$, et al. Obesity, adipokines and cancer: an update. Clin Endocrinol. 2015:83(147-156)

17. Booth A, Magnuson A, Fouts J, Foster M. Adipose tissue, obesity and adipokines: role in cancer promotion. Horm Mol Biol Clin Investig. 2015;21: $57-74$

18. Mazen R, Khaldi A, Al F, Kapila K. Associations of single nucleotide polymorphisms in the adiponectin gene with adiponectin levels and cardiometabolic risk factors in patients with cancer. Dis Markers. 2011;30:197-212.

19. Méndez-Hernández A, Gallegos-Arreola MP, Moreno-Macías H, Espinosa Fematt J, Pérez-Morales R. LEP rs7799039, LEPR rs1137101, and ADIPOQ rs2241766 and 1501299 polymorphisms are associated with obesity and chemotherapy response in Mexican women with breast Cancer. Clin Breast Cancer. 2017:17:453-62.

20. Ausubel FM. Short protocols in molecular biology : A compendium of methods from current protocols in molecular biology. 2nd ed. (green pub. Associates). Brooklyn: Wiley; 1992.

21. National Center for Biotechnology Information (NCBI). 1000 Genomes Browser. Available from: [https://www.ncbi.nlm.nih.gov/variation/tools/1 000genomes/]. Accessed 6 Apr 2020.

22. Bieńkiewicz J, Smolarz B, Malinowski A. Association between single nucleotide polymorphism +276G > T (rs1501299) in ADIPOQ and endometrial Cancer. Pathol Oncol Res. 2016:22:135-8.

23. Gui MH, et al. Association of the adiponectin gene rs1501299 G>T variant, serum adiponectin levels, and the risk of coronary artery disease in a Chinese population. Diabetes Res Clin Pract. 2012;97:499-504.

24. Li Q, et al. Five common haplotype-tagging variants of adiponectin (ADIPOQ) and cancer susceptibility: a meta-analysis. Genet Test Mol Biomarkers. 2014;18:417-24.

25. Llorca J, Prieto-Salceda D, Combarros O, Dierssen-Sotos T, Berciano J. Competing risks of death and hardy-Weinberg equilibrium in case-control studies of gene-disease association. Gac Sanit. 2005:19:321-4.

26. Macías-Gómez NM, et al. ADIPOQ rs2241766 SNP as protective marker against DIBC development in Mexican population. PLoS One. 2019;14:1-10.

\section{Publisher's Note}

Springer Nature remains neutral with regard to jurisdictional claims in published maps and institutional affiliations.

Ready to submit your research? Choose BMC and benefit from:

- fast, convenient online submission

- thorough peer review by experienced researchers in your field

- rapid publication on acceptance

- support for research data, including large and complex data types

- gold Open Access which fosters wider collaboration and increased citations

- maximum visibility for your research: over $100 \mathrm{M}$ website views per year

At $\mathrm{BMC}$, research is always in progress.

Learn more biomedcentral.com/submission 